\title{
DEVELOPMENT OF WOOD GRINDING
}

\section{GRINDING MODEL}

\author{
BRUNO LÖNNBERG \\ Pulping Technology, Åbo Akademi University, Åbo, Finland \\ \Corresponding author: Professor Emeritus B. Lönnberg, blonnber@abo.fi
}

Dedicated to Prof. Dr. Cr. I. Simionescu, on his $100^{\text {th }}$ birth anniversary

\begin{abstract}
The aim of this study was to develop and test a model expected to be useful in interpretation of stone grinding of wood. Since stone grinding has been in use for about two centuries, it is surprising that some grinding mechanisms still remain undiscovered. The application of an energy balance set-up for the wood and grindstone surfaces, valid for wood grinding under conditions presenting continuity, resulted in a useful model.

The theoretical model developed suggests that the ratio of the compression and tension powers, called the power ratio, depends linearly on the specific production. The experimental grinding data tested in this context follow the theoretical model. Hence, it would be a valuable tool in further evaluation of grinding and groundwood data.
\end{abstract}

Keywords: balance, energy, grinding, mechanism, modelling, power, wood

\section{INTRODUCTION}

Mechanical fiberising of wood has been developed for years in the direction of higher demand of fiberising energy and higher pulp strength, but unfortunately lower pulp yield. However, increasing energy prices will favour classical stone grinding, which has been in use for about two centuries. Stone grinding converts the wood almost totally into paper-making fibres and fines, and accordingly, it appears as a potential mechanical fiberising method in the future, if further improved. The improvement would be probable if the mechanism of grinding is understood properly.

In fact, the development of the stone grinding process requires knowledge of not only the fiberising mechanism, but also the grindstone surface and the wood raw material properties, as well as of their role in the grinding mechanism. Specific information has been collected about wood grinding on a mill scale and in laboratories, but proper understanding of the process seems to be still lacking. This research paper is intended to start scientific evaluation of the stone grinding of wood for technical improvements.

\section{DEVELOPMENT OF A MODEL}

A theoretical energy balance that is descriptive for stone grinding of wood should include the heated wood and stone surfaces. The friction between the stone and wood surfaces produces heat, which modifies the visco-elastic properties of the wood surface and its fibres. The total mechanical energy and heat introduced per unit of time equal the heat leaving the balance area. ${ }^{1,2}$ Mechanical compression and simultaneous tension treat the wood surface in the balance area. Hence, the corresponding powers are also introduced into the balance area, along with the specific heat of the moist wood, and finally, the specific energy of the heated fibres and the moisture leave the balance area:

$F_{\mathrm{c}} v_{\mathrm{c}}+F_{\mathrm{t}} v_{\mathrm{t}}+\dot{G}_{\mathrm{w}} c_{\mathrm{w}} T_{\mathrm{w}}+\dot{G}_{\mathrm{m}} c_{\mathrm{m}} T_{\mathrm{m}}=$

$=\dot{G}_{\mathrm{w}} c_{\mathrm{w}} T_{\mathrm{p}}+\dot{G}_{\mathrm{m}} c_{\mathrm{m}} T_{\mathrm{p}}+Q$

In Equation (1), the symbols represent: $F-$ force, $v$ - speed, $\dot{G}$ - mass flow, $c$ - specific heat, $T$ - temperature and $Q$ - heat losses, while the subscripts have the following meaning: $c$ compression, $t-$ tension, $w$ - wood (fibres), $m-$ moisture in wood and $p$ - pulp of fibres. As the energy balance is valid for continuity, the effects of shower water quantity and temperature may be neglected for the energy balance suggested.

If $Q \approx 0$ as in continuity of a permanent process, and if the temperatures of the entering wood and its moisture are assumed equal, as well as the temperatures of the wood fibres and their 
moisture leaving the balance area, the model changes as follows:

$F_{\mathrm{c}} v_{\mathrm{c}}+F_{\mathrm{t}} v_{\mathrm{t}}+\left(\dot{G}_{\mathrm{w}} c_{\mathrm{w}}+\dot{G}_{\mathrm{m}} c_{\mathrm{m}}\right) T_{\mathrm{w}} \approx$

$\approx\left(\dot{G}_{\mathrm{w}} c_{\mathrm{w}}+\dot{G}_{\mathrm{m}} c_{\mathrm{m}}\right) T_{\mathrm{p}}$

When $F_{\mathrm{c}} v_{\mathrm{c}}$ is replaced by $P_{\mathrm{c}}$, the compression power, and $F_{\mathrm{t}} v_{\mathrm{t}}$ by $P_{\mathrm{t}}$, the tension power, and when $\left(T_{\mathrm{p}}-T_{\mathrm{w}}\right)$ is replaced by $\Delta T_{\mathrm{p}-\mathrm{w}}$, the model can be simplified as follows:

$$
P_{\mathrm{c}}+P_{\mathrm{t}} \approx\left(\dot{G}_{\mathrm{w}} c_{\mathrm{w}}+\dot{G}_{\mathrm{m}} c_{\mathrm{m}}\right) \Delta T_{\mathrm{p}-\mathrm{w}}
$$

If all the terms are divided by $P_{\mathrm{t}}$ and the moisture-to-dry wood ratio $\left(\dot{G}_{\mathrm{m}} / \dot{G}_{\mathrm{w}}\right)$ is replaced by $X$, the model changes further:

$$
\left(P_{\mathrm{c}} / P_{\mathrm{t}}\right)+1 \approx\left(c_{\mathrm{w}}+X c_{\mathrm{m}}\right) \Delta T_{\mathrm{p}-\mathrm{w}}\left(\dot{G}_{\mathrm{w}} / P_{\mathrm{t}}\right)
$$

where $\left(\dot{G}_{\mathrm{w}} / P_{t}\right)$ represents the specific production in units of $(\mathrm{kg} / \mathrm{h}) / \mathrm{kW}$ or $\mathrm{kg} / \mathrm{kWh}$, which, in fact, is the inverse of the specific energy, $\mathrm{kWh} / \mathrm{kg}$.

\section{MODEL TESTING}

The obtained model would be useful in the interpretation of wood grinding, provided that the basic experiments have been performed under controlled conditions. The model is indicating that $\left(P_{\mathrm{c}} / P_{\mathrm{t}}\right)$ as a function of $\left(\dot{G}_{\mathrm{w}} / P_{\mathrm{t}}\right)$ would represent a linear function $y=\mathrm{a} x+\mathrm{b}$, where the gradient $\mathrm{a}=$ $\left(c_{\mathrm{w}}+X c_{\mathrm{m}}\right) \Delta T_{\mathrm{p}-\mathrm{w}}$. The power ratio expresses simultaneously slow and rapid movements, produced by the stone surface during grinding. Theoretically, mainly slow and perpendicular compression by the grindstone is produced in the wood surface, which probably generates viscoelastic movements in the fibres. Simultaneously, mainly rapid and tangential tension is causing breakage in the outmost fibres and distortion in the inner fibres of the fibre layer heated. Accordingly, the power ratio might be descriptive also for basic groundwood pulp and paper properties, such as fibre length distribution and "fines" particles of the pulp, as well as for the tensile strength and light scattering of the paper sheet.

If the experimental grinding data obtained for wood, plotted in a $\left(P_{\mathrm{c}} / P_{\mathrm{t}}\right)$ vs $\left(\dot{G}_{\mathrm{w}} / P_{\mathrm{t}}\right)$ diagram, form a linear relationship, it indicates that the model developed is probably descriptive for stone grinding of wood. If so, the gradient of the linear function is represented by $\left(c_{\mathrm{w}}+X c_{\mathrm{m}}\right) \Delta T_{\mathrm{p}-\mathrm{w}}$. Since the specific heats of wood and water are nearly constant, only $X$, the moisture-to-wood ratio and $\Delta T_{\mathrm{p}-\mathrm{w}}$, the temperature increase of the fibre pulp in grinding, are potentially applicable quantities.
Examples clarify the relationship between the power ratio and the specific production of wood grinding data, provided that they were produced by a technically advanced experimental grinder, by selecting the wood samples carefully, by application of a well-conditioned grindstone and by following standardised preparation and testing methods. The wood grinding apparatus was successfully planned and constructed, and it was presented together with the first grinding results in a Master's thesis. ${ }^{3}$ Forest spruce (Picea abies L.) was used in the grinding studies. Its moisture content and basic density were typically around $55 \%$ and $350 \mathrm{~kg} / \mathrm{m}^{3}$, respectively. In this particular case, the grindstone was a Norton A601-N7VG, suitable for grinding of newspaper pulp, sharpened with a spiral roll no. $10 / 28^{\circ}$ to a depth of $0.6 \mathrm{~mm}$ and opened with a pitch roll no. 24, and finally conditioned with $\mathrm{SiC}$ powder in two stages by 120 and 180 mesh powder, respectively. Unpressurised grinding was performed under the following conditions: shower water $-80{ }^{\circ} \mathrm{C}$, stone speed $-10,20$ and $30 \mathrm{~m} / \mathrm{s}$, and the wood feeding rate was varied between 0.5 and $1.0 \mathrm{~mm} / \mathrm{s}$.

In accordance with the model, Figure 1 suggests that there exists a linear relationship between the power ratio and the specific production in stone grinding at 30,20 and $10 \mathrm{~m} / \mathrm{s}$. The gradient $\mathrm{a}=0.41$, the intercept $\mathrm{b}=-0.17$ and the coefficient of determination $\mathrm{R}^{2}=0.80$. Unexpectedly, however, there were no clear differences between the various stone speeds used in this investigation, but further studies, also including pulp and paper properties, may provide new insights.

Another example of grinding is based on the data collected in a Master's thesis ${ }^{4}$ that focused on pressure grinding of spruce wood at moisture contents of $65,58,44,28$ and $15 \%$, respectively. Figure 2 indicates that fresh wood represented, in this context, by 65 and $58 \%$ moisture content (MC) forms, surprisingly, together with $15 \% \mathrm{MC}$, a specific linear function for grinding with $\mathrm{a}=$ $0.41, R^{2}=0.93$ and $b=-0.017$. The slightly drier wood samples represented by 44 and $28 \%$ MC again have $\mathrm{a}=0.29, \mathrm{~b}=0.026$ and $\mathrm{R}^{2}=0.91$. The clearly higher gradient of the fresh wood and one dry wood sample indicates that grinding now is more sensitive to changes in specific production, than in the case of wood of relatively low moisture content, the limits of which, however, are still unknown. 


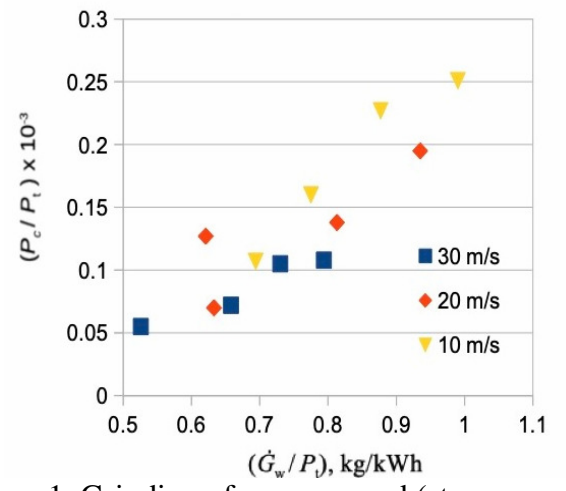

Figure 1: Grinding of spruce wood (stone speed 30, 20 or $10 \mathrm{~m} / \mathrm{s}$ )

\section{CONCLUSION}

This study indicates that an energy balance may be useful for the development of a model for evaluating stone grinding data. As suggested by the developed model, grinding data applied for calculation of the specific production $\left(\dot{G}_{\mathrm{w}} / P_{\mathrm{t}}\right)=x$ and the power ratio $\left(P_{\mathrm{c}} / P_{\mathrm{t}}\right)=y$ probably form linear functions, $y=\mathrm{a} x+b$. The initial tests applying the developed energy balance appeared successful for the grinding data used in this context.

It seems that grinding with widely varied stone speeds $(30,20$ and $10 \mathrm{~m} / \mathrm{s})$ did not affect the linear function significantly, since $\mathrm{R}^{2}$ was as high as 0.80 . However, the gradient was the same as that for fresh wood. It was interesting to reveal that wood with relatively low moisture content, in this context between 44 and $28 \%$, reacted differently in stone grinding, since the gradient was significantly lower, which indicates that wood below certain moisture content is less sensitive to changes in the specific production.

Grinding results may probably be explained and understood properly by application of an energy balance model. Hopefully, the wood

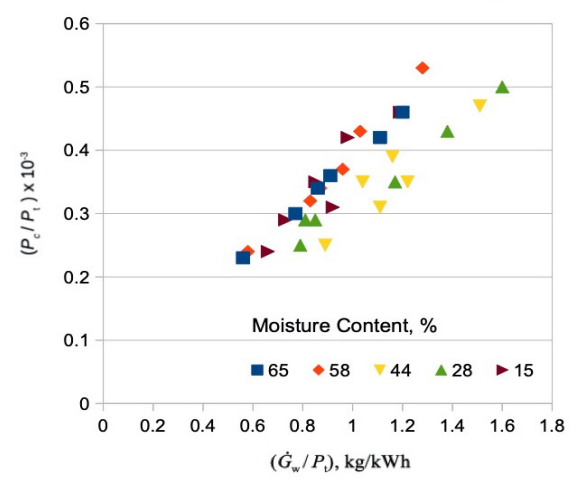

Figure 2: Pressure grinding of spruce wood

grinding process can be developed further to meet the demands of the future, where wood and energy will apparently become more expensive. Also, to be successful in the future, stone grinding of wood requires deeper knowledge about the effects of wood quality, stone material and its pattern, as well as grinding conditions.

\section{REFERENCES}

1 B. Lönnberg, in Procs. $9^{\text {th }}$ Fundamental Mechanical Pulp Research Seminar, Trondheim, Norway, May 19-20, 2015, Extended abstract

2 B. Lönnberg, O. Tuovinen and P. Fardim, in Procs. $10^{\text {th }}$ Fundamental Mechanical Pulp Research Seminar, Jyväskylä, Finland, June 13-14，2017， Extended abstract, https://afrc.fi/fmprs2017/

3 J.-A. Fagerhed, M. Tech. Thesis, Åbo Akademi University, Faculty of Chemical Technology, Åbo, 1987, 57 p., conducted by Prof. B. Lönnberg, Laboratory of Pulping Technology, https://www.abo.fi/en/fct-masters-theses/

4 M. Riissanen, M. Tech. Thesis, Åbo Akademi University, Faculty of Chemical Technology, Åbo, 2002, 70 p., conducted by Prof. B. Lönnberg, Laboratory of Pulping Technology, https://www.abo.fi/en/fct-masters-theses/ 